\title{
DIAGNÓSTICO DAS ÁREAS VERDES PÚBLICAS DO BAIRRO POTENGI, NATAL-RN
}

L. H. V. BARROS, V. P. SILVA*, G. A. ALVES, L. G. PINHEIRO, I. NASCIMENTO, P. K. L. DIAS, R. F. A. OLIVEIRA, V.

A. SANTANA, W. A. OLIVEIRA, C. S. C. MEDEIROS e B. S. F. F. GOMES

Instituto Federal de Educação, Ciência e Tecnologia do Rio Grande de Norte lianaviana17@yahoo.com.br*

Artigo submetido em maio/2015 e aceito em setembro/2015

DOI: $10.15628 /$ holos.2015.3036

\section{RESUMO}

Este estudo teve por objetivo diagnosticar as principais áreas verdes do bairro Potengi, localizado na Região Administrativa Norte de Natal-RN. A metodologia adotada consistiu, principalmente, de levantamentos bibliográfico e documental e, posteriormente, de pesquisa de campo, por meio da qual foi possível se visitar ruas, praças, canteiros e passeios públicos do bairro. A detecção das áreas verdes se deu inicialmente com o uso do google Earth. Os resultados apontaram que as áreas verdes do bairro Potengi estão em torno de $2,20 \mathrm{~km}^{2}$ de extensão, correspondendo a uma taxa de $27,54 \%$ do território da região. As principais praças e canteiros visitados dispõem de árvores de pequeno a médio portes. Conclui-se que as áreas verdes públicas do bairro Potengi estão concentradas basicamente nas praças e canteiros centrais das principais ruas e avenidas. O percentual de arborização do bairro apresenta-se pouco significativo, requerendo com isso um maior envolvimento das populações locais e do poder público no sentido de se ampliar a arborização dos passeios públicos, visto que a presença de áreas verdes no espaço urbano é fator de extrema relevância para o bem-estar da população. Além disso, devido a importância das áreas verdes para a melhoria da qualidade de vida, o estudo constatou, ainda, a falta de investimento público no que tange a manutenção e revitalização das áreas verdes públicas.

PALAVRAS-CHAVE: Diagnóstico. Áreas verdes públicas. Planejamento ambiental. Bairro Potengi.

\section{DIAGNOSIS OF PUBLIC GREEN AREAS IN THE POTENGI NEIGHBORHOOD, NATAL-} RN

\begin{abstract}
This study aimed to diagnose the main green areas of the Potengi neighborhood, located in the North Administrative Region of Natal-RN. The methodology consisted mainly of bibliographic and documentary surveys and subsequently field research, through which it was possible to visit streets, squares, flowerbeds and public tours of the neighborhood. Detection of green areas initially occurred with the use of Google Earth. The results showed that the green areas of the Potengi neighborhood are around 2.20 square kilometers in length, corresponding to a rate of $27.54 \%$ of the territory of the region. The main squares and sites visited have small to medium-sized trees. It concludes
\end{abstract}

that public green areas of the Potengi neighborhood are concentrated basically in the squares and medians of the main streets and avenues. The afforestation percentage of the neighborhood presents negligible, requiring hence a greater involvement of local people and government in order to expand afforestation of public footpaths, as the presence of green areas in urban areas is extreme factor relevance to the people's welfare. Also, because the importance of green spaces to improve the quality of life, the study found, though, the lack of public investment regarding the maintenance and revitalization of public green areas.

KEYWORDS: Diagnose. Public green areas. Environmental planning. Potengi Neighborhood. 


\section{INTRODUÇÃO}

A população urbana tem passado por uma fase de intenso crescimento, trazendo com isso uma série de consequências que impactam diretamente o meio ambiente. Essas consequências ganham notoriedade, principalmente, pela elevação do consumo humano de produtos industrializados, a ausência ou o mal planejamento do uso dos recursos naturais, bem como por uma ocupação desordenada e degradante dos ambientes urbanos. Nesse aspecto, a situação atual de degradação ambiental tem se tornado uma preocupação frequente, devido ao fato das populações urbanas dependerem, cada vez mais, de forma direta do ambiente natural para a sua sobrevivência (PEREIRA et al., 2007).

O crescimento intenso da população e a ocupação desordenada do solo urbano têm requerido, cada vez mais, o conhecimento da situação ambiental dos territórios ocupados para, em seguida, contribuir com informações para o planejamento ambiental de melhoria das condições espaciais urbanas. Isso diz respeito ao fato das ocupações desordenadas das cidades (com a redução da cobertura vegetal urbana, por exemplo) estarem afetando a qualidade de vida da população, e o conhecimento das atuais condições ambientais contribuírem para a preservação do meio ambiente e, por conseguinte, para a sustentabilidade urbana.

Nessa perspectiva, o diagnóstico, como parte do conhecimento de componentes de uma dada área territorial, pode se constituir numa etapa importante para elaboração do planejamento ambiental do espaço urbano. Esse tipo de planejamento pode ser definido, segundo Floriano (2004), como sendo a organização do trabalho para consecução de objetivos comuns, de forma que os impactos resultantes da ação humana que afetam negativamente 0 ambiente sejam minimizados e os positivos sejam maximizados. Portanto, pode-se afirmar que o diagnóstico da situação em que se encontram os recursos naturais torna-se importante, pois o mesmo pode trazer à tona a caracterização simples e complexa das condições ambientais de uma determinada área, favorecendo o estabelecimento de metas para a preservação e a relação harmoniosa entre o ser humano e o seu meio ambiente.

No atual contexto de problemas e mudanças ambientais relevantes, as áreas verdes urbanas vêm se destacando como ambientes que precisam ser diagnosticados, devido sua importância para à manutenção da qualidade de vida, o conforto ambiental de populações citadinas, bem como servirem de embelezamento de espaços públicos, ou servindo muitas vezes como as únicas sombras de ruas e avenidas das cidades. As árvores existentes em espaços urbanos funcionam como importantes filtros ambientais e amenizadoras de fortes índices de calor, insolação e diminuição de ventos e ruídos, reduzindo diversos tipos de poluições e problemas ambientais. No entanto, quando inexistem ou são mal planejadas, as áreas verdes podem evidenciar problemas de grande magnitude e se tornarem em focos de conflitos urbanos.

As áreas verdes são definidas, por Morero et al. (2007), como sendo locais onde predominam a vegetação arbórea, podendo ser encontradas em praças, jardins e parques, além de canteiros centrais de ruas e avenidas e passeios públicos, de forma que sua distribuição sirva a toda população e atinja as necessidades reais e os anseios para o lazer. No que diz respeito ao seu domínio público, a resolução CONAMA № 369/2006, em seu Art. 8오 § 1ำ, tem definido como sendo espaços dotados de vegetação e espaços livres de impermeabilização que desempenham função ecológica, paisagística e recreativa, propiciando assim a melhoria da qualidade estética, funcional e ambiental da cidade. Nesse contexto, as áreas verdes podem apresentar tanto 
vantagens ecológicas, quanto cênicas e sociais, exercendo papel fundamental no tange à composição da paisagem urbana, como pontuam Benini e Martin (2010). Tomando por suporte as palavras desses autores, entende-se área verde pública como sendo

todo espaço livre (área verde/lazer) que foi afetado como de uso comum e que apresente algum tipo de vegetação (espontânea ou plantada), que possa contribuir em termos ambientais (fotossíntese, evapotranspiração, sombreamento, permeabilidade, conservação da biodiversidade e mitigue os efeitos da poluição sonora e atmosférica) e que também seja utilizado com objetivos sociais, ecológicos, científicos ou culturais (BENINI; MARTIN, 2010, p. 77).

$\mathrm{Na}$ cidade de Natal, as áreas verdes públicas estão espraiadas por espaços livres como calçadas, ruas, praças, canteiros, bairros e regiões administrativas (Norte, Sul, Leste e Oeste) de maneira distintas e desiguais. Em alguns bairros da cidade, a exuberância da cobertura vegetal evidencia-se principalmente pela ampla presença de árvores da paisagem urbana (concentrada somente em praças e canteiros), mas em outros bairros, as áreas verdes se restringem a pontos isolados ou a pequenas manchas de árvores, que podem ficar muito aquém dos índices de cobertura vegetal indicados pela Sociedade Brasileira de Arborização Urbana (SBAU), que é de $15 \mathrm{~m}^{2} /$ habitante, como sendo o mínimo de áreas verdes públicas ideais a qualidade de vida. Dentre as áreas de menor arborização da cidade de Natal-RN, os bairros situados na Região Administrativa Norte (RAN) têm se destacados negativamente, e dentre eles o bairro Potengi tem sido um dos que dispõe de somente $2,2 \mathrm{~km}^{2}$ de áreas verdes (NATAL, 2010).

A partir do exposto, o presente estudo teve por objetivo principal diagnosticar as principais áreas verdes do bairro Potengi, localizado na Região Administrativa Norte da cidade de Natal-RN.

\section{METODOLOGIA: LOCALIZAÇÃO GEOGRÁFICA, MATERIAIS E MÉTODOS}

A área de estudo compreende o bairro Potengi, situado geograficamente na região Administrativa Norte da cidade de Natal-RN. Os materiais e métodos adotados foram basicamente a pesquisa bibliográfica, a análise documental e a pesquisa de campo, realizada pelas principais ruas do bairro e documentada por imagens fotográficas das principais áreas verdes existentes, como pode ser visto mais detalhadamente a seguir, nstas duas subseções.

\subsection{LOCALIZAÇÃO e Caracterização do bairro Potengi}

O Potengi é um dos maiores bairros da Região Administrativa Norte da cidade de Natal, formado por diversos conjuntos habitacionais (Mapa 1). Esse bairro teve sua ocupação iniciada em 1975 com a construção dos primeiros conjuntos habitacionais, podendo ser considerado como um dos mais antigos dessa região geográfica da cidade. O bairro Potengi é constituído pelos seguintes conjuntos habitacionais: Potengi, Soledade I, Panorama I e II, Panatis I e III, Promorar e Panatis II, Santa Catarina, Soledade II, Santarém, Morada I e II, APERN e Planície das Mangueiras (NATAL, 2011). A formação desses conjuntos habitacionais resultou na expansão territorial do bairro, contribuindo para o crescimento das atividades de serviços e comerciais, 0 
qual sedia atualmente o maior número equipamentos urbanos dessa região geográfica da cidade, como shopping, hipermercados, hospitais, escolas, praças, dentre outros (NATAL, 2015).

O bairro Potengi foi criado por meio da Lei $4.328 / 93$ e possui atualmente uma área de $1.024,79 \mathrm{Km}^{2}$. Ele dispõe de 22.723 domicílios particulares permanentes e uma população residente de cerca de 79.759 habitantes, segundo os dados do Censo Demográfico de 2010 do IBGE (NATAL, 2015). Nesse bairro, a taxa de crescimento da população residente, de acordo com pesquisas realizadas entre os anos de 2000 a 2013, foi de 4,00 e a densidade demográfica em 2013 estava em torno de 91,87 hab./ha. Esse bairro está situado, mais precisamente, na Zona Adensável $2^{1}$, segundo as leis complementares números 07/94 e 22/99 ou planos diretores da cidade de Natal. Nessa zona são incentivados os usos não residenciais, para os quais o coeficiente de aproveitamento máximo é de 4,5. Para o uso residencial, a densidade máxima prescrita é a básica de 225 hab./ha. O estoque de área edificável é de $150.000 \mathrm{~m}^{2}$ para uso não residencial, estabelecendo, para essa zona, o coeficiente de aproveitamento máximo de 1,8 e a densidade máxima de 225 hab./ha.

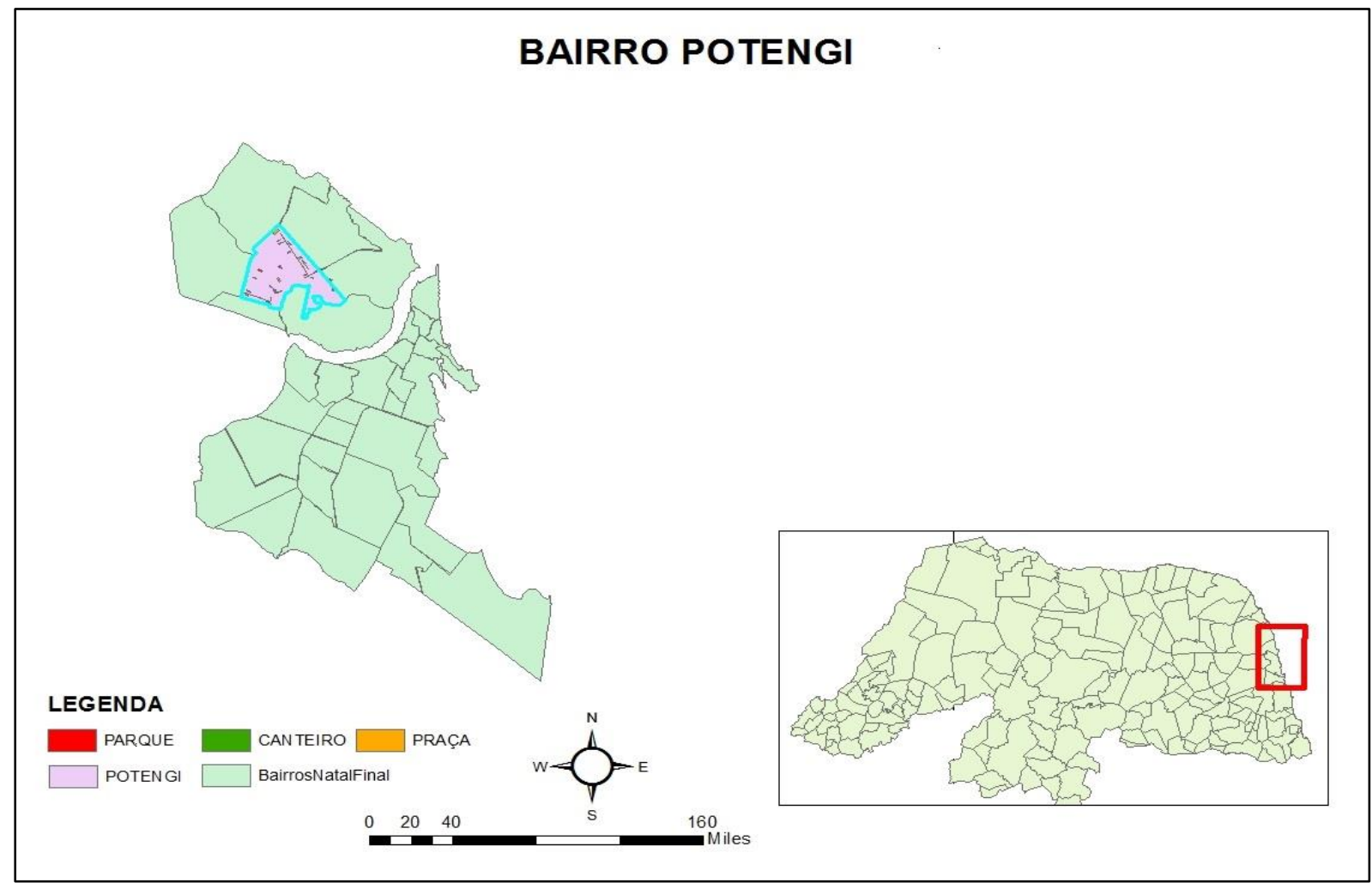

Mapa 1 - Localização do bairro Potengi na Região Administrativa Norte da cidade de Natal-RN Fonte: NATAL (2010).

\subsection{MATERIAIS E MÉTODOS DO DIAGNÓSTICO DAS AREAS VERDES PÚBLICAS}

Por se tratar de uma pesquisa exploratória e descritiva, na perspectiva de Gil (2010), a metodologia empregada adotou-se, basicamente, o exame da literatura pertinente de trabalhos científicos como artigos, livros, etc., sobre a temática em estudo. Além desse tipo de pesquisa,

\footnotetext{
${ }^{1}$ Zona Adensável diz respeito à zona onde as condições do meio físico, a disponibilidade de infraestrutura e a necessidade de diversificação de uso possibilitem um adensamento maior do que aquele correspondente aos parâmetros básicos de Densidade e Coeficiente de Aproveitamento. A Zona Adensável está dividida, para efeito dos critérios de sua utilização, em Zona Adensável 1 e 2.
} 
outra etapa importante do estudo foram as consultas a legislação urbanística e aos documentos disponibilizados pela Secretaria Municipal de Meio Ambiente e Urbanismo (SEMURB) da Prefeitura de Natal. Antes de realizar a pesquisa de campo, primeiramente identificou-se as áreas verdes públicas do bairro Potengi, utilizando dessa vez a ferramenta do google Earth. Após essa identificação, realizou-se a pesquisa de campo, por meio da qual se fez uso de uma planilha de levantamento de dados, coletando-se dados referentes às ruas, as praças, aos passeios públicos com presença de arborização. Utilizou-se, também, máquina fotográfica para o registro das principais áreas verdes públicas do bairro. A coleta de dados ocorreu no decorrer do ano de 2015. Ao final, os dados coletados foram sistematizados e, em seguida, analisados à luz dos suportes teóricos adotados, os quais contribuíram para a decifração das áreas verdes públicas do bairro Potengi da cidade de Natal-RN.

\section{DECIFRANDO AS ÁREAS VERDES PÚBLICAS DO BAIRRO POTENGI DE NATAL-RN: UM DIAGNÓSTICO}

Entende-se que decifrar as áreas verdes públicas do bairro Potengi, significa trazer à baila a leitura, a tradução ou a decodificação da situação atual em que se encontra os espaços públicos em relação as suas dimensões de arborização. Ou melhor dizendo, significa diagnosticar as condições reais de áreas verdes públicas existentes nesse bairro da cidade de Natal, como está sendo decifrado a seguir.

\section{1 ÁREAS VERDES PÚBLICAS DO BAIRRO POTENGI: DESTAQUE DE ALGUMAS PRAÇAS}

Com a realização pesquisa, constatou-se que os bairros da Região Administrativa Norte da cidade de Natal-RN possuem uma cobertura vegetal média de $2,9 \mathrm{~km}^{2}$. No bairro Potengi, a área de cobertura vegetal compreende $2,2 \mathrm{~km}^{2}$ estando na média em relação aos principais bairros, conforme apresentado na tabela 1. Os dados disponibilizados pela Secretaria Municipal de Meio Ambiente e Urbanismo da cidade de Natal apontam para uma área de cobertura vegetal de 2,20 $\mathrm{km}^{2}$, correspondendo a uma taxa de $27,54 \%$ de cobertura vegetal. Dos 7 bairros que compõem a região ou zona norte de Natal-RN, o bairro Potengi ficou em $4^{\circ}$ lugar no ranking da presença de áreas com vegetação entre os bairros da Zona Norte, de acordo com os dados da SEMURB (NATAL, 2010).

Tabela 1: Cobertura vegetal dos bairros da Região Administrativa Norte da cidade de Natal-RN.

\begin{tabular}{|c|c|c|c|c|}
\hline \multicolumn{5}{|c|}{ Cobertura vegetal dos bairros da Zona Norte - 2010} \\
\hline & Bairro & $\begin{array}{l}\text { Área total } \\
\left(\mathrm{km}^{2}\right)\end{array}$ & $\begin{array}{l}\text { Área de cobertura vegetal } \\
\qquad\left(\mathrm{km}^{2}\right)\end{array}$ & $\begin{array}{c}\text { Taxa de cobertura vegetal } \\
(\%)\end{array}$ \\
\hline \multirow{7}{*}{$\begin{array}{c}\text { Região } \\
\text { Administrativa } \\
\text { Norte }\end{array}$} & Lagoa azul & 11,67 & 2,32 & 19,86 \\
\hline & Igapó & 2,20 & 0,41 & 18,71 \\
\hline & $\begin{array}{l}\text { Nossa Senhora da } \\
\text { Apresentação }\end{array}$ & 10,25 & 2,65 & 25,87 \\
\hline & Pajuçara & 7,66 & 3,29 & 42,89 \\
\hline & Potengi & 8,00 & 2,20 & 27,54 \\
\hline & Redinha & 8,79 & 5,58 & 63,47 \\
\hline & Salinas & 10,31 & 4,02 & 38,99 \\
\hline Subtotal & & 58,88 & 20,47 & 34,76 \\
\hline
\end{tabular}

Fonte: Natal (2010). 
As áreas verdes do bairro Potengi compreendem, principalmente, praças e canteiros de ruas e avenidas. Algumas das principais praças do bairro possuem estrutura e manutenção adequadas, embora parte considerável desses ambientes não disponham de infraestrutura para atividades de recreação e afins, como equipamentos impróprios para uso da população do entorno, bancos e calçadas destruídos pela ação depredatória e temporal, sem as mínimas condições de utilização.

A estrutura organizacional das praças e canteiros na sua maioria é deficiente e essa condição tem sido resultante da falta de manutenção por parte do poder público municipal. Diante disso, percebeu-se que a utilidade desses espaços tem sido comprometida em virtude da falta de investimentos em melhoria das áreas verdes públicas e, consequentemente, modificando a intenção social de uso.

Por ocasião da pesquisa de campo ao bairro Potengi, realizada em praticamente todos os conjuntos, seguindo os percursos de limites dos bairros (Quadro 2), procurou-se vistoriar as condições de uso e os níveis de arborização de praças, ruas e canteiros centrais. Por meio de orientações geográficas, demarcadas pelo uso de GPS, foram definidos os pontos do bairro que foram observados, visando o diagnóstico de presenças de áreas verdes públicas existentes, as quais foram fotografas ela equipe responsável por esse diagnóstico.

Constatou-se que as áreas verdes do bairro estão mais concentradas nas praças e, em seguida, nos canteiros centrais das principais ruas e avenidas. Pode-se constatar, ainda, que as principais áreas verdes foram vistas nas praças visitadas (Figuras 1 a 4), apresentando arborização de pequeno e médio portes, constituindo-se em espaços destinados para atividades de recreação, mesmo com a presença de poucas árvores existentes.

Quadro 2: Percurso de limite do bairro de Natal-RN.

\begin{tabular}{|c|c|c|c|c|}
\hline INÍCIO & $\begin{array}{l}\text { DIREÇÃO - EIXO } \\
\text { IMAGINÁRIO }\end{array}$ & SENTIDO & TÉRMINO & OBSERVAÇÕES \\
\hline \multirow{10}{*}{$\begin{array}{l}\text { Encontro das ruas } \\
\text { Irmã Vitória com as } \\
\text { Avenidas Acaraú e } \\
\text { das Fronteiras }\end{array}$} & Avenida das Fronteiras & $\begin{array}{c}\text { Avenida } \\
\text { Acaraú/Via Férrea }\end{array}$ & Via Férrea & \multirow{10}{*}{$\begin{array}{l}\text { Eixo do muro } \\
\text { limite }\end{array}$} \\
\hline & Via Férrea & À esquerda & Rua Votuporanga & \\
\hline & Rua Votuporanga & À direita & $\begin{array}{c}\text { Avenida Gov. } \\
\text { Antônio de Melo e } \\
\text { Souza }\end{array}$ & \\
\hline & $\begin{array}{c}\text { Avenida. Gov. Antônio de } \\
\text { Melo e Souza }\end{array}$ & À direita & Rio Jaguaribe & \\
\hline & Rio Jaguaribe & À direita & $\begin{array}{l}\text { Limite do conjunto } \\
\text { Potengi }\end{array}$ & \\
\hline & Limite do conjunto Potengi & À direita & Via Férrea & \\
\hline & Via Férrea & À esquerda & $\begin{array}{c}\text { Rua Prof. Paulo } \\
\text { Nobre }\end{array}$ & \\
\hline & Rua Prof. Paulo Nobre & À direita & $\begin{array}{l}\text { Rua João Medeiros } \\
\text { Filho }\end{array}$ & \\
\hline & Rua João Medeiros Filho & À direita & Avenida Acaraú & \\
\hline & Avenida Acaraú & À esquerda & Ponto inicial & \\
\hline
\end{tabular}

Fonte: Os autores (2015). 
Utilizando-se dos percursos demarcados pela pesquisa, viu-se que a praça da Bíblia, identificada como sendo uma das principais áreas verdes públicas do bairro Potengi, tem passado por alguns problemas, como podem ser vistos pela Figura 1 e evidenciam os depoimentos de alguns moradores: "A praça está acabada não tem mais estrutura de praça, muito lixo. Hoje virou terminal de ônibus". Ou no dizer de outro, "A praça está muito acabada, se não fosse isso seria um lugar ótimo para o lazer nos fins de tarde". Como pode ser visualizado pela Figura 1, a praça da Bíblia apresenta árvores de grande porte, mas está precisando de um maior cuidado por parte do poder público ou daqueles que são responsáveis pela manutenção e viabilização de um melhor espaço de qualidade de vida para os citadinos do bairro Potengi.

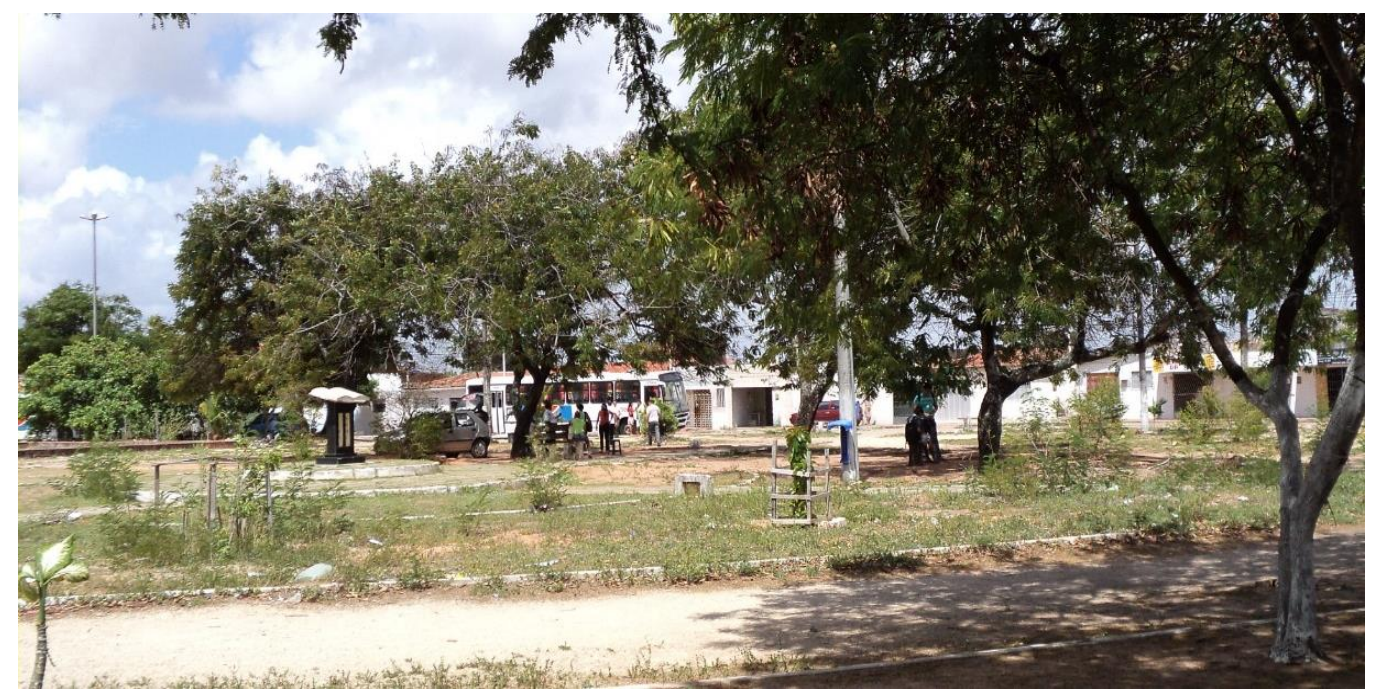

Figura 1: Praça da Bíblia.

Fonte: Os autores (2015).

Outra importante área verde pública, identificada por ocasião da pesquisa, é a praça Sorocaba, situada no bairro Potengi (Figura 2). Dispondo de arvores de portes médios, essa praça tem se constituído em mais um dos poucos nichos de predomínio de vegetação do bairro, mesmo que as condições infraestruturais e de equipamentos não sejam uma das melhores, comprometendo as necessidades de lazer da população local, como pode visualizado pela figura.

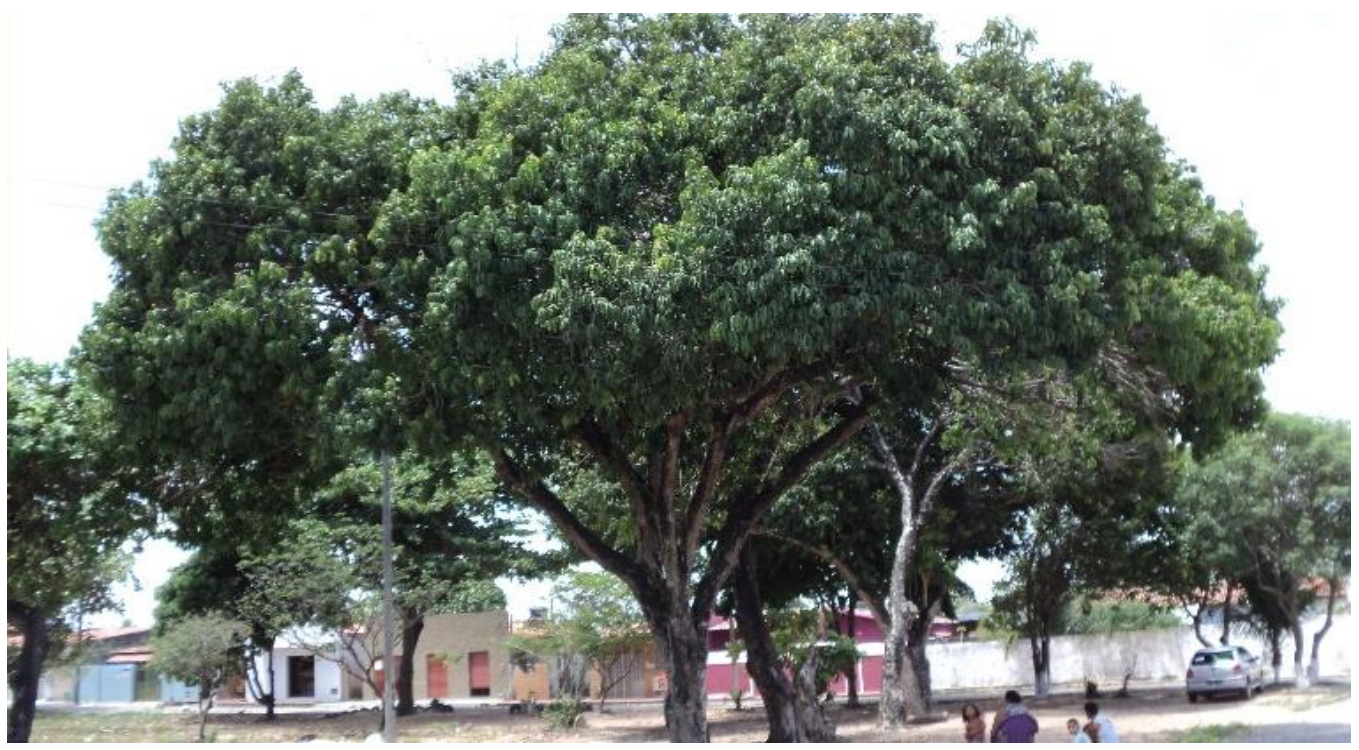

Figura 2: Praça Sorocaba.

Fonte: Os autores (2015). 
A praça Sumaré (Figura 3), localizada no bairro Potengi, é outra área verde pública de destaque desse diagnóstico, devido ser um importante ambiente de cobertura vegetal, mas que tem passado pelos mesmos problemas de infraestrutura e de revitalização por parte do poder público, o que tem dificultado o seu uso como mais um espaço de lazer por parte das pessoas residentes no bairro. Entende-se que, para que a praça se torne útil e efetiva, segundo Barros e Virgílio (2003),

é necessário que a mesma esteja provida de elementos naturais e antrópicos, tais como vegetação de porte diferenciado, quadras poliesportivas, playground, áreas sem pavimentação, bancos, árvores etc., e que sua distribuição espacial seja democrática e atenda a totalidade da população.

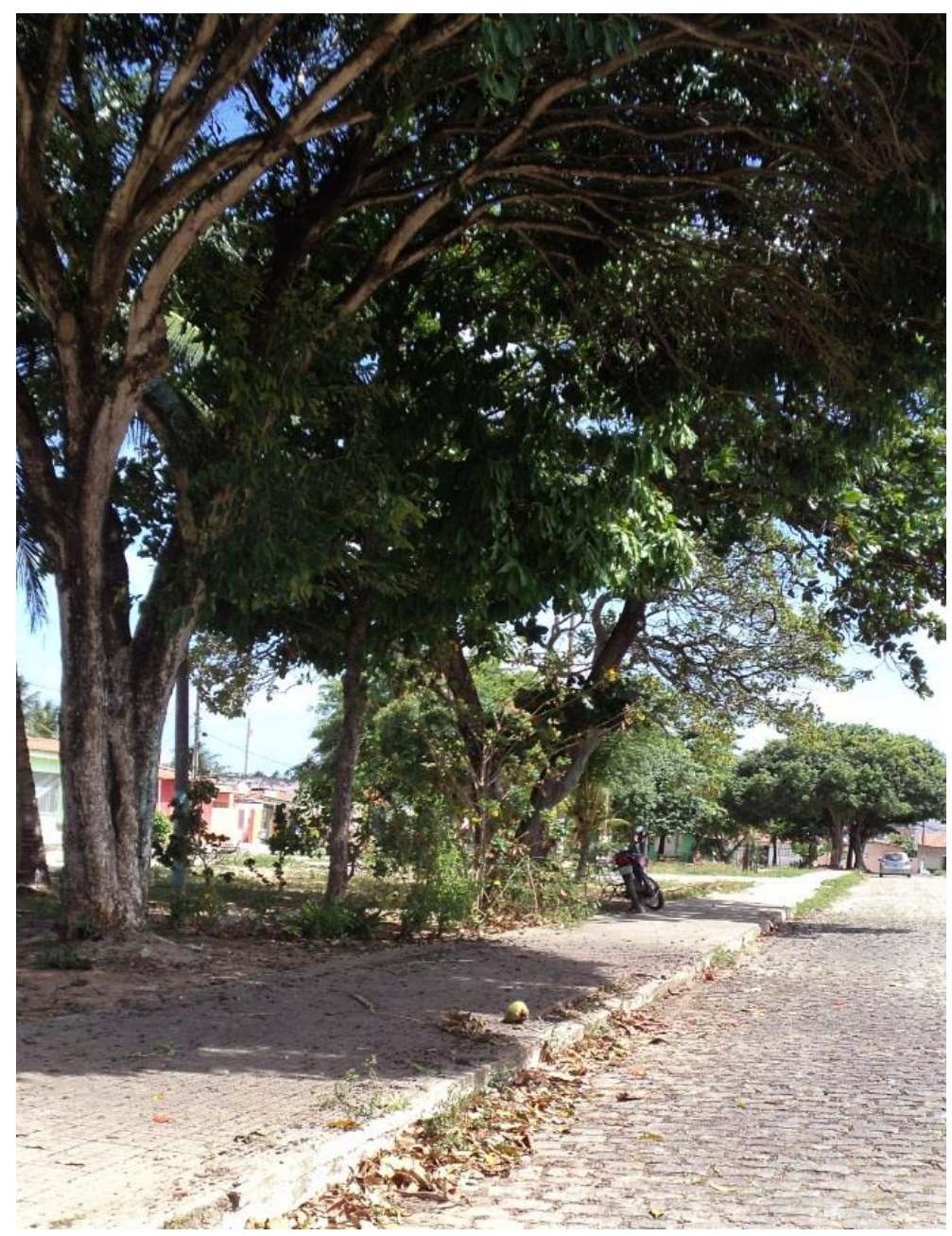

Figura 3: Praça Sumaré

Fonte: Os autores (2015).

A equipe elaboradora do diagnóstico das áreas verdes públicas do bairro Potengi visitou a Praça Alto Paraná (Figura 4). A imagem que se viu foi de um ambiente desprovido de quaisquer elementos naturais e sociais, como vegetação e infraestrutura adequada para o seu uso. As poucas presenças de árvores ficam situadas nos quintais das residências mais próximas. Além de se constituir num verdadeiro depósitos de materiais de construção civil. 


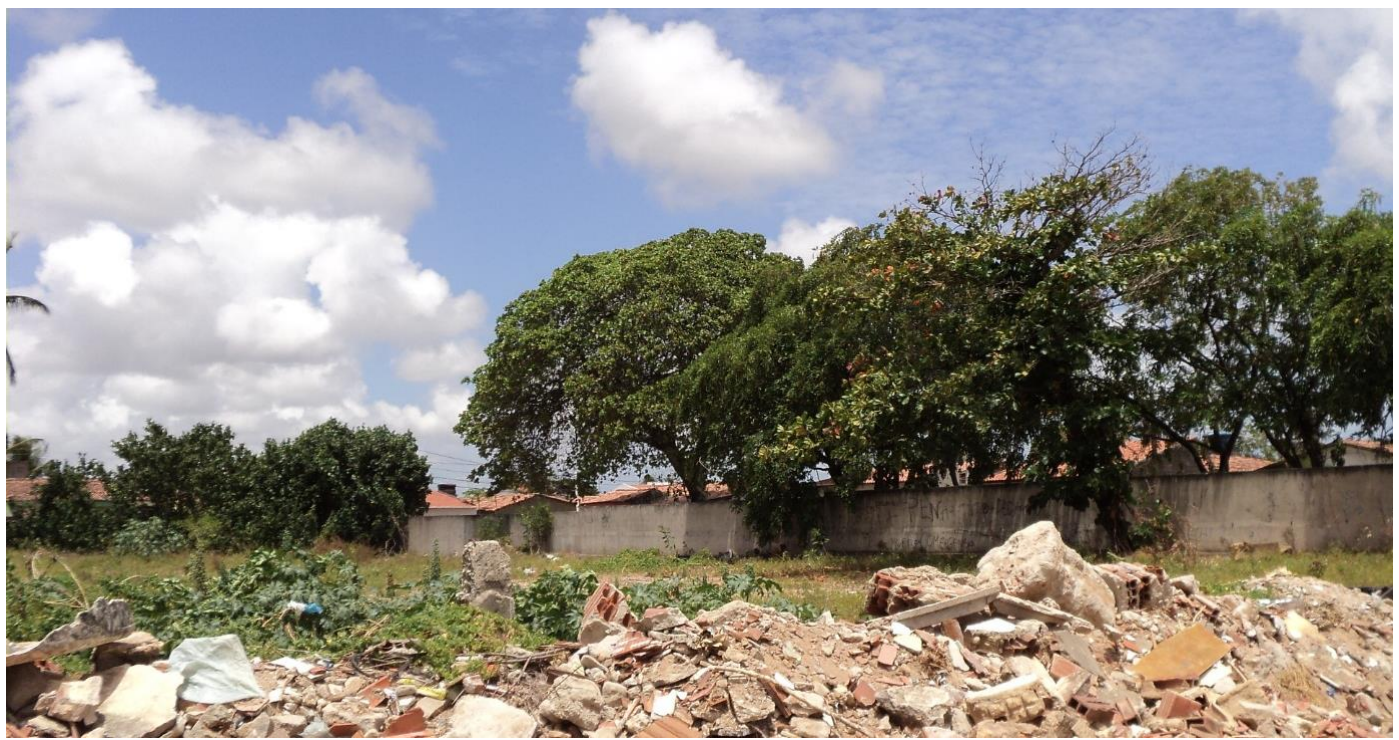

Figura 4: Praça Alto Paraná

Fonte: Os autores (2015).

Além de praças e canteiros de ruas e avenidas, as áreas verdes públicas do bairro Potengi podem ser contempladas pela presença de um horto florestal, o qual contribui para melhorar das condições ambientais locais.

\subsection{HORTO MUNICIPAL DE NATAL}

O horto Municipal de Natal constitui um dos espaços públicos onde há o maior adensamento de cobertura vegetal, conforme pode ser visualizado na Figura 5 . Localizado no Conjunto Santa Catarina, no bairro Potengi, o horto florestal pode ser caraterizado como a maior área verde pública do bairro. Trata-se de um espaço pertencente ao Departamento de Paisagismo da Secretaria de Serviços Urbanos (SEMSUR) da cidade de Natal, o qual é responsável pela manutenção do local onde é feita a produção, o cultivo e a distribuição de mudas, voltadas para a arborização. No horto são então acolhidos os instrumentos e suprimentos utilizados no plantio, tais como sacos plásticos, adubos e ferramentas necessárias para a produção das mudas.

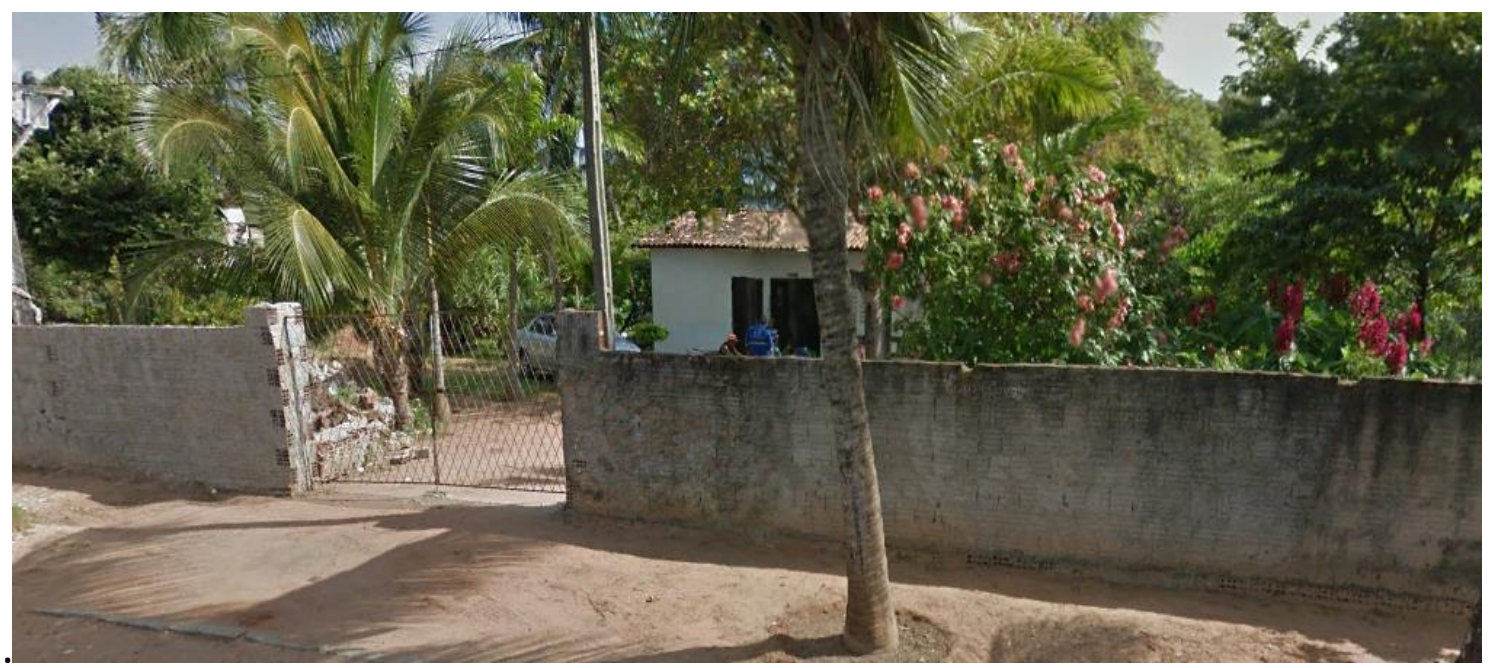

Figura 5 - Horto Municipal de Natal

Fonte: Os autores (2015). 


\subsection{O DIAGNÓSTICO DE ARBORIZAÇÃO E A CONDIÇÃO ESTRUTURAL}

A partir dos levantamentos realizados com o google Earth e das visitas de campo nas principais avenidas do bairro Potengi, representadas pelas avenidas Fronteiras, João Medeiros Filho, Paulistana, Votuporanga, Itapetinga e Aracaú, constatou-se ainda que as áreas verdes públicas do bairro são escassas e mal distribuídas, estando presentes principalmente em praças e canteiros de ruas e avenidas, além da área de cobertura do horto florestal.

Procurando dimensional, os percentuais de áreas verdes de avenidas e canteiros do bairro, foram elaborados, a seguir, gráficos baseados em dados de quantificação e comparação das dimensões das avenidas ao tamanho dos canteiros presentes nas mesmas ao longo do trecho e a presença de cobertura verde. O percentual existente foi então calculado por meio de regra simples entre a área da avenida e a área dos canteiros e a cobertura de vegetação presentes.

Os Gráficos 1 e 2 apresentam dados com relação à cobertura vegetal do bairro Potengi. 0 Gráfico 1 apresenta as dimensões de área das principais avenidas e canteiros do bairro e o quantitativo de áreas verdes existentes em metros quadrados. O gráfico 2 apresenta informações no que diz respeito à cobertura verde dos canteiros das principais avenidas do bairro.

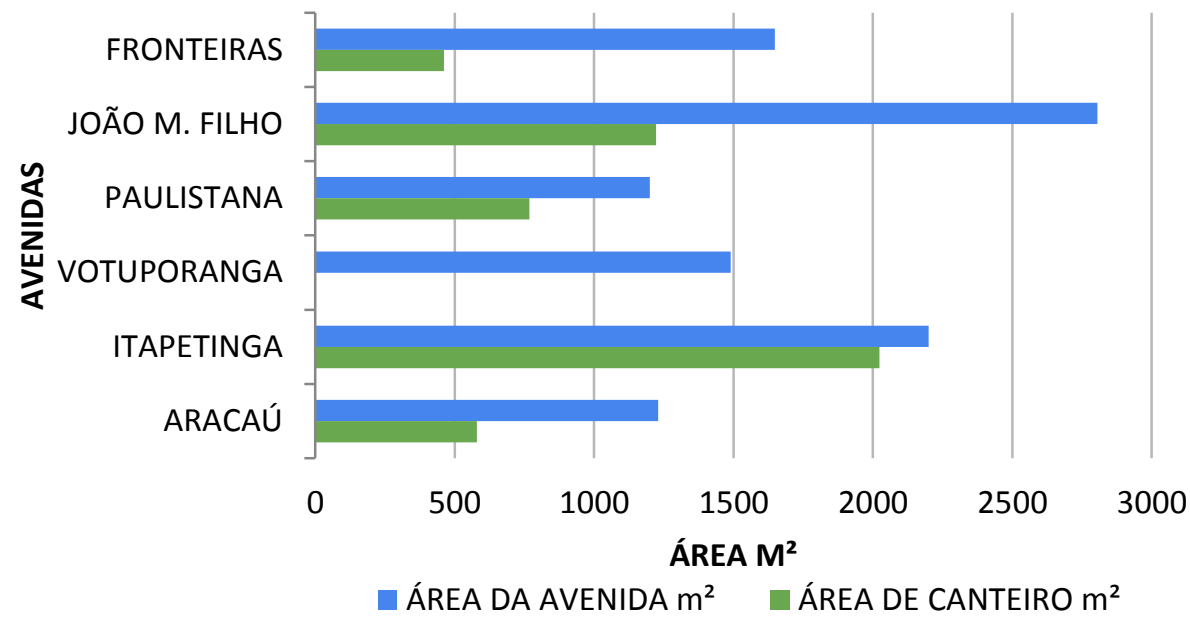

Gráfico 1: Área de canteiro das principais avenidas do bairro Potengi $\left(\mathrm{m}^{2}\right)$. Fonte: Os autores (2015).

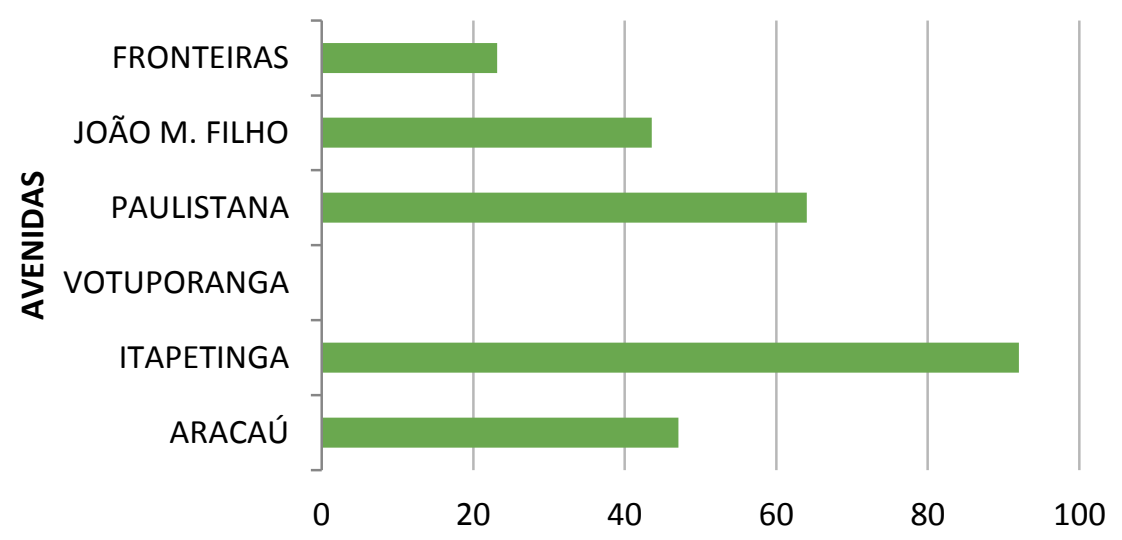

PORCENTAGEM DE COBERTURA VERDE EM CANTEIROS

Gráfico 2: Cobertura verde dos canteiros das avenidas Fonte: Os autores (2015). 
A partir da análise dos gráficos pode-se perceber que a Avenida João Medeiros Filho, maior avenida do bairro, possui cerca de $2.805 \mathrm{~m}^{2}$ de áreas verdes, representando a segunda maior área de canteiros centrais, equivalente a 1.222,33 $\mathrm{m}^{2}$. No entanto, apesar de sua grande extensão, sua área verde correspondente foi de apenas $43,57 \%$.

A Avenida Itapetinga, segunda maior avenida do bairro com aproximadamente $2.200 \mathrm{~m}^{2}$ de extensão, resultou em uma maior área de canteiros, destacando-se com 92\% de cobertura vegetal. Já a Avenida Votuporanga, apesar de ser a quarta maior avenida do bairro, não dispõe de canteiros arborizados. Quanto às avenidas das Fronteiras, Paulistana e Aracajú, as mesmas apresentaram 1.648,28 $\mathrm{m}^{2}, 1.200 \mathrm{~m}^{2}$ e $1.230 \mathrm{~m}^{2}$ respectivamente. Por outro lado, as áreas de canteiros centrais dessas três avenidas foram de $461,72 \mathrm{~m}^{2}, 768,65 \mathrm{~m}^{2}$ e $579,35 \mathrm{~m}^{2}$ respectivamente, o que corresponde a $23,13 \%, 64,05 \%$ e $47,1 \%$ de cobertura vegetal de cada uma dessas avenidas.

Os resultados desse diagnóstico mostram que a arborização do bairro Potengi tem se concentrado principalmente pela plantação de árvores de pequeno e médio portes em praças, canteiros centrais de principais ruas e em algumas calçadas. Mesmo que presente em poucos espaços públicos do bairro, entende-se que a presença de áreas verdes em maior dimensão ou a arborização dos espaços públicos é essencial a qualquer planejamento urbano, visto que as mesmas têm funções importantíssimas, como: propiciar sombra, purificar o ar, atrair aves, diminuir a poluição sonora, constituir como fator estético e paisagístico, diminuir o impacto das chuvas, contribuir para o balanço hídrico, valorizar a qualidade de vida local, assim como contribuir com a valorização econômica das propriedades de seu entorno (CABRAL, 2013).

Portanto, pela condição jurídica de bem de uso comum do povo, as áreas verdes naturais ou arborizadas podem e devem ser protegidas legalmente pela coletividade, através das associações de bairro por meio da ação civil pública, como prever a lei 7.347/85, ou ainda pelo Ministério Público, ou pelo cidadão comum, através da ação popular possibilitada pela lei 4.717/65. Afinal, por sua importância socioambiental, as áreas verdes públicas devem ser caracterizadas para que planejamentos ambientais urbanos eficientes e sustentáveis sejam propostos e postos em prática pelos tomadores de decisão urbanos.

\section{CONSIDERAÇÕES FINAIS}

Conclui-se que as áreas verdes públicas do bairro Potengi estão presentes nas praças e canteiros centrais das principais ruas e avenidas. O percentual de arborização do bairro apresenta-se pouco significativo, o que requer um maior envolvimento das populações locais e do poder público no sentido de se ampliar a arborização dos passeios públicos, visto que a presença de áreas verdes no espaço urbano é fator de extrema relevância para o bem-estar da população. Além do aspecto cênico, as áreas verdes urbanas contribuem para a formação de microclimas e para a preservação do meio ambiente, sendo esses alguns dos inúmeros benefícios da arborização diante do crescimento em larga escala das zonas urbanas.

Constatou-se, ainda, com a realização do diagnóstico que o bairro Potengi dispõe de uma importante área verde pública, como o Horto Municipal, localizado no Conjunto Santa Catarina. O horto produz, cultiva e distribui mudas para a arborização da cidade. 
No entanto, conclui-se que as condições de abandono ou a falta de manutenção/revitalização de muitas das áreas verdes do bairro Potengi demonstram a falta de compromisso e envolvimentos dos órgãos públicos e da própria sociedade local. Tendo em vista a importância desempenhada pelas áreas verdes, torna-se evidente a necessidade de haver maiores investimentos para que se diagnostique a situação e condições de manutenção dessas áreas. Nesse sentido, destaca-se que um bom planejamento ambiental de áreas verdes de ruas, bairros e cidade só será possível mediante um minucioso diagnóstico da situação em que se encontram essas áreas e da sensibilidade da comunidade por meio de ações de sustentabilidade, imprescindíveis para o sucesso de uma cidade arborizada e de boa qualidade para se viver bem.

\section{REFERÊNCIAS BIBLIOGRÁFICAS}

1. BARROS, M. V. F.; VIRGILIO, H. Praças: espaços verdes na cidade de Londrina. In: GEOGRAFIA. 12., 2003, Londrina. Anais...Londrina: Universidade Estadual de Londrina, 2003. p. 533 - 544.

2. BENINI, S. M.; MARTIN, E. S. Decifrando as áreas verdes públicas. Revista Formação, São Paulo, v.2, n. 17, p. 63-80, 2010.

3. BRASIL. Constituição (1988). Resolução do CONAMA n³69, de 28 de março de 2006. Diário Oficial [da] República Federativa do Brasil, Poder Executivo. Brasília, DF, 29 mar.2006, n.61, Seção I, p. 150-151.

4. CABRAL, P. I. D. Arborização urbana: problemas e benefícios. Especialize on-line, Goiania, v.01, n.6, p. 15, dez. 2013.

5. FlORIANO, E. P. Planejamento ambiental. Caderno Didático, Santa Rosa, 1.ed., n.6, 2004. $54 p$.

6. MORERO, A. M.; SANTOS, R. F.; FIDALGO, E. C. C. Planejamento ambiental de áreas verdes: estudo de caso de Campinas-SP. Revista do Instituto Florestal, v. 19, n. 1, 2007. p. 19-30.

7. NATAL. Secretaria Municipal de Meio Ambiente e Urbanismo. Anuário. Rio Grande do Norte. 2011.

8. Natal 2003: conheça melhor a nossa cidade. Natal: Prefeitura do Natal, 2003. 1 CDROM.

9. Lei Complementar $n^{\circ} 07$ de 1994 e n²2 de 1999. Plano Diretor de Natal.

10. Lei Municipal n 4330, de 1993. Criação do Bairro Potengi.

11. N_ Natal: mapa informativo. Disponível em: <file:///C:/Users/valdenildo/Down loads/MAPA_2014_FRENTE.pdf>. Acesso em: 25 jul. 2015.

12. PEREIRA, C. E. F. et al. Aspectos relevantes na relação população x meio ambiente. Sinapse Ambiental, Minas Gerais, v. 4, n.2, dez. 2007. 